\title{
Investigating the biocontrol and anti-biofilm potential of a three phage cocktail against Cronobacter sakazakii in different brands of infant formula
}

\author{
Lorraine Endersen ${ }^{\mathrm{a}}$, Colin Buttimer ${ }^{\mathrm{a}}$, Eoghan Nevin ${ }^{\mathrm{a}}$, Aidan Coffey ${ }^{\mathrm{a}}$, Horst Neve ${ }^{\mathrm{b}}$, Hugo Oliveira ${ }^{\mathrm{c}}$, \\ Rob Lavigne ${ }^{\mathrm{d}}$, Jim O'Mahony ${ }^{\mathrm{a}, *}$ \\ ${ }^{a}$ Department of Biological Sciences, Cork Institute of Technology, Cork, Ireland \\ b Department of Microbiology and Biotechnology, Max Rubner-Institute, Federal Research Institute of Nutrition and Food, 1, Kiel, Germany \\ c CEB-Centre of Biological Engineering, LIBRO - Laboratório de Investigação em Biofilmes Rosário Oliveira, University of Minho, $4710-057$ Braga, Portugal \\ d Laboratory of Gene Technology, KU-Leuven, Leuven, Belgium
}

\section{A R T I C L E I N F O}

\section{Keywords:}

Bacteriophages

Biocontrol

Biofilm

Cronobacter sakazakii

Infant formula

\begin{abstract}
A B S T R A C T
In recent years, the microbiological safety of powdered infant formula has gained increasing attention due to the identification of contaminating C. sakazakii and its epidemiological link with life-threatening neonatal infections. Current intervention strategies have fallen short of ensuring the production of infant formula that is free from C. sakazakii. In this study, we describe the isolation and characterisation of three bacteriophages (phages) and their application as a phage cocktail to inhibit the growth of $C$. sakazakii in different brands of infant formula, while also assessing the phages ability to prevent biofilm formation. All three phages, isolated from slurry, possess a relatively broad host range, verified by their ability to infect across genera and species. When all three phages were combined and used as part of a phage cocktail, $73 \%$ coverage was obtained across all Cronobacter strains tested. Optimum thermo-tolerance and $\mathrm{pH}$ stability were determined between $4{ }^{\circ} \mathrm{C}-37^{\circ} \mathrm{C}$, and $\mathrm{pH}$ 6-8, respectively, well within the normal range of application of infant formula. Genome sequencing and analysis revealed all the phages to be free from lysogenic properties, a trait which renders each favourable for phage therapy applications. As such, the combined-phage preparation $\left(3 \times 10^{8} \mathrm{pfu} / \mathrm{mL}\right)$ was found to possess a strong bactericidal effect on C. sakazakii/C. sakazakii LUX cells ( $\leq 10^{4} \mathrm{cfu} / \mathrm{mL}$ ), resulting in a significant reduction in cell numbers, to below the limit of detection ( $<10 \mathrm{cfu} / \mathrm{mL}$ ). This was observed following a $20 \mathrm{~h}$ challenge in different brands of infant formula, where samples in the absence of the phage cocktail reached concentrations of $\sim 10^{9} \mathrm{cfu} / \mathrm{mL}$. The phage cocktail also demonstrated promise in preventing the establishment of biofilm, as biofilm formation could not be detected for up to $48 \mathrm{~h}$ post treatment. These results highlight the potential application of this phage preparation for biocontrol of $C$. sakazakii contamination in reconstituted infant formula and also as a preventative agent against biofilm formation.
\end{abstract}

\section{Introduction}

Cronobacter spp. (formally Enterobacter sakazakii) consists of a diverse group of Gram-negative, facultatively anaerobic, motile bacilli belonging to the Enterobacteriaceae family (Iversen et al., 2007). The genus comprises seven species: Cronobacter sakazakii, Cronobacter malonaticus, Cronobacter turicensis, Cronobacter universalis, Cronobacter muytjensi, Cronobacter dublinensis and Cronobacter condiment (Brady et al., 2013; Joseph et al., 2012). In recent years, C. sakazakii has gained significant attention as an emerging food-borne pathogen due to the associated link between infectious disease and the consumption of contaminated foods, in particular, reconstituted infant milk formula.
While $C$. sakazakii is responsible for causing severe clinical infections in immunocompromised individuals of all ages, it is pre-term, low-birth weight infants who are most at risk (FAO/WHO 2008; Healy et al., 2010). Clinical symptoms of infection in infants include meningitis, bacteraemia and severe forms of necrotising enterocolitis, with case fatality rates ranging between 40 and $80 \%$ (Friedemann, 2009). These high mortality rates and the fact that many survivors are very often left with chronic neurological and developmental disorders, highlights the damaging effect this organism has on infant health (Forsythe, 2005; Lai, 2001). Accordingly, The International Commission for Microbiological Specifications for Foods has ranked C. sakazakii as a "Severe hazard for restricted populations, life threatening or substantial chronic sequelae

\footnotetext{
* Corresponding author at: Department of Biological Sciences, Cork Institute of Technology, Cork, Ireland.

E-mail addresses: lorraine.endersen@mycit.ie (L. Endersen), colin.buttimer@mycit.ie (C. Buttimer), eoghan.nevin@mycit.ie (E. Nevin), aidan.coffey@cit.ie (A. Coffey), horst.neve@mri.bund.de (H. Neve), hugooliveira@deb.uminho.pt (H. Oliveira), rob.lavigne@kuleuven.be (R. Lavigne), jim.omahony@cit.ie (J. O'Mahony).
} 
of long duration", placing the organism in the same category as Clostridium botulinum, Cryptosporidium parvum and Listeria monocytogenes (types A and B) (ICMSF, 2002).

C. sakazakii is ubiquitous in nature with many studies indicating that plant material is its primary niche (in particular vegetables, fruits, cereals, wheat, rice, herbs and spices). However, other more pertinent sources also found to harbour this pathogen include powdered infant formula (PIF) and milk powder manufacturing environments (Friedemann, 2007; Kandhai et al., 2004).

C. sakazakii possess physiological traits which affords its ability to survive in such environments and thus permit PIF to serve as a prime vehicle for transmission to the immunocompromised infant. These traits include, (1) resistance to desiccation and osmotic stress (Breeuwer et al., 2003), (2) an extended temperature growth range (Iversen and Forsythe, 2004), (3) thermo-tolerance compared to other Enterobacteriaceae found in PIF (Nazarowec-White and Farber, 1997a, 1997b), and (4) the ability to form biofilms on a range of different materials including polycarbonate which is often used to make babies bottles (Iversen and Forsythe, 2004).

PIF is not manufactured as a sterile preparation and hence can become contaminated with $C$. sakazakii during production. Although the organism is effectively inactivated during pasteurisation (Nazarowec-White and Farber, 1997a, 1997b), contamination is likely to occur from the addition of non-sterile ingredients during manufacture. Indeed, it has been suggested that PIF ingredients originating from plant material, which have not been heat treated are a potential source of C. sakazakii contamination (Healy et al., 2010). Other possible sources of contamination include the use of non-sterile equipment during processing or reconstitution, and from temperature abuse of the reconstituted formula itself (Al-Nabulsi et al., 2009).

Capsular polysaccharides on the outer surface of $C$. sakazakii cells play a central role in biofilm formation, giving the organism the ability to attach and colonise a variety of surfaces including stainless steel, glass, latex, polycarbonate, silicon and polyvinyl chloride (PVC) (Iversen et al., 2004). The bacterial cells embedded in a matrix of exopolymeric substances, are physiologically distinct from their planktonic counterparts. These cells demonstrate changes in growth rate and gene transcription and often exhibit a significantly higher tolerance to antibiotics ( $\leq 1000$ times higher) and other sanitising agents. The presence of persister cells, the reduced metabolic activity present in the inner layers of the biofilm and the decreased penetration of antibiotics through the exopolymeric matrix, all contribute to this increased resistance (Donlan and Costerton, 2002; Keren et al., 2004). As a result, complete elimination is very often compromised and re-infection commonly occurs.

Consequently, the microbiological safety of PIF is under continuous scrutiny as a result of contaminating C. sakazakii and its epidemiological link with life-threatening neonatal infections (Forsythe, 2005; Himelright, 2002; Hunter and Bean, 2013). The destructive economic impact the pathogen has on healthcare systems and PIF production facilities due to contaminated product recalls is also apparent (Chenu and Cox, 2009). Indeed, there is a growing requirement for the development of new and effective mechanisms to further prevent $C$. sakazakii contamination in both food, and the food processing environment.

Bacteriophages (phages) and their derivatives are well recognised for their antibacterial properties, demonstrating promise as natural, safe and effective alternatives for the prevention, treatment and/or eradication of foodborne pathogens in a range of different foods and food processing environments. These include, decontamination of livestock, sanitation of contact surfaces and equipment, in addition to biocontrol of raw meats, fresh foods and vegetables (Endersen et al., 2014; Goodridge and Bisha, 2011), cheese (Carlton et al., 2005), readyto-eat (RTE) foods (Bigot et al., 2011), skim milk (Ellis et al., 1973; Endersen et al., 2013), and reconstituted infant formula (Kim et al., 2007), all of which demonstrate their applicability for use at each stage of the food production process. ListShield ${ }^{\mathrm{TM}}$, approved for use in the US in 2006 as a processing aid to control Listeria monocytogenes in meat and poultry products, marked the arrival of the first phage-based product to the commercial marketplace in the Western world (Bren, 2006). Following this significant development, several phage related products have been approved for use in the US, including preparations active against the prominent foodborne pathogens, E. coli O157:H7, Salmonella, and additional preparations against L. monocytogenes (Endersen et al., 2014; Goodridge and Bisha, 2011). The pioneering anti-listeria phage-based preparation is now registered in Europe as an organic food additive and has also been approved for use as a food processing aid by the Food Standards Australia \& New Zealand, highlighting the fact that phage-based preparations are continuing to gain global acceptance as safe and effective alternatives for the biocontrol of harmful foodborne pathogens (Fsanz, 2012; Hodgson, 2013).

Here we report the isolation and characterisation of three phages against the opportunistic, foodborne, infant formula pathogen, $C$. sakazakii. In addition, we demonstrate the efficacy of the phages, used as part of a phage cocktail, at inhibiting the growth of $C$. sakazakii in four different brands of reconstituted infant milk formula while also assessing the phages ability to prevent biofilm formation.

\section{Materials and methods}

\subsection{Bacterial strains and growth media}

The following strains were used in this study: C. sakazakii ATCC BAA 894, C. sakazakii ATCC BAA 894 LUX, C. sakazakii DPC 6258, C. muytjensi ATCC 51329, C. sakazakii ATCC 29004, and C. sakazakii DPC 8155. These were sourced from the Dairy Products Research Centre, DPC, Moorepark, Fermoy, Co. Cork, Ireland. Strains were stored at $-80^{\circ} \mathrm{C}$ and routinely grown on Luria-Bertani (LB) agar, in LB broth and in some cases supplemented with $1 \%$ or $2.5 \% \mathrm{D}-(+)$-glucose at $37^{\circ} \mathrm{C}$. HiChrome ${ }^{\mathrm{TM}}$ Cronobacter spp. Agar, Modified (14,763, Sigma Aldrich) was used for selective growth of $C$. sakazakii when necessary. Selective growth of $C$. sakazakii ATCC BAA 894 LUX was achieved by the addition of $500 \mu \mathrm{g} / \mathrm{mL}$ erythromycin to LB broth/agar.

\subsection{Isolation of phages}

Phages were isolated from slurry, sourced from a cattle farmer in Clonakilty, West Cork, Ireland, using methods described previously (Carlson, 2005). Briefly, each sample (5 mL) was added to equal volumes of LB broth (Sigma Aldrich, UK), supplemented with $10 \mathrm{mM}$ $\mathrm{CaCl}_{2}$ (Sigma Aldrich) and inoculated with a mid-log phase C. sakazakii ATCC BAA 894 culture. Samples were incubated overnight at $37^{\circ} \mathrm{C}$ with shaking. Samples were centrifuged at $4000 \mathrm{~g}$ for $15 \mathrm{~min}$ to pellet cells and debris. The supernatant was filtered through a $0.45 \mu \mathrm{M}$ filter and the filtrate was re-enriched with mid-log phage $C$. sakazakii culture two more times. The supernatant obtained from the final enrichment step was filter-sterilised and tested for the presence of viable infective phages by adding $100 \mu \mathrm{L}$ of the filtrate to $100 \mu \mathrm{L}$ of early log phase $C$. sakazakii cells in a $5 \mathrm{~mL} \mathrm{LB} 0.4 \% \mathrm{w} / \mathrm{v}$ overlay agar tube tempered to $50{ }^{\circ} \mathrm{C}$ and subsequently poured onto the surface of a LB $1.5 \% \mathrm{w} / \mathrm{v}$ agar plate. Plates were incubated at $37^{\circ} \mathrm{C}$ overnight and then examined for phage plaques.

\subsection{Phage purification and amplification}

Presumptive phages were purified by successive single plaque isolation and were routinely propagated on C. sakazakii ATCC BAA 894 as previously described (O'Flaherty et al., 2005). Briefly, a single isolated plaque was aseptically picked from a lawn of $C$. sakazakii ATCC BAA 894 on LB agar using a sterile capillary tube and added to $100 \mu \mathrm{L}$ of early-log phase culture. The sample was incubated at $37^{\circ} \mathrm{C}$ overnight. The resulting lysate was centrifuged, filter sterilised and serially 
diluted followed by standard plaque assay on C. sakazakii, as described previously. Single plaque purification was repeated twice, after which purified phage was recovered. The phage titre was assessed using a spot plaque assay method, where $10 \mu \mathrm{L}$ of serial dilutions of each phage suspension were spotted onto $C$. sakazakii seeded indicator plates. Plates were incubated at $37{ }^{\circ} \mathrm{C}$ overnight and spot dilutions were subsequently examined for the presence of plaques. High titre phage suspensions were obtained by adding $5 \mathrm{~mL}$ of phage buffer $(50 \mathrm{mM}$ Tris $\mathrm{pH} 8,150 \mathrm{mM} \mathrm{NaCl}, 10 \mathrm{mM} \mathrm{MgCl}_{2}, 2 \mathrm{mM} \mathrm{CaCl}_{2}$ ) to a standard plaque assay plate revealing confluent lysis. Phages were recovered by aseptically running sterile hockey sticks across the surface of the agar plate to physically recover the phages, incubating for $2 \mathrm{~h}$ at $37^{\circ} \mathrm{C}$ with shaking. The buffer was then recovered from the plate, centrifuged to pellet debris and filter sterilised using a $0.45 \mu \mathrm{m}$ filter. Again, phage titres were assessed using a spot plaque assay technique as described previously. The purified high-titre phage solutions were stored at $4{ }^{\circ} \mathrm{C}$.

\subsection{Phage DNA preparation}

Phage DNA isolation and restriction analysis were carried out as previously described (Kropinski and Clokie, 2009). Briefly, $18 \mu \mathrm{L}$ of $1 \mathrm{mg} / \mathrm{mL}$ DNAse I (Fischer Scientific, 11873795) and $8 \mu \mathrm{L}$ of $12.5 \mathrm{mg} /$ $\mathrm{mL}$ RNase A (Sigma-Aldrich) were added to $1.8 \mathrm{~mL}$ aliquots of phage lysate. Samples were mixed and incubated at $37^{\circ} \mathrm{C}$ for $30 \mathrm{~min}$ in order to remove host genomic contaminants. Subsequently, $92 \mu \mathrm{L}$ of $10 \%$ SDS and $18 \mu \mathrm{L}$ of $10 \mathrm{mg} / \mathrm{mL}$ proteinase $\mathrm{K}$ (Roche) were added. Following further $30 \mathrm{~min}$ incubation at $65{ }^{\circ} \mathrm{C}$, proteins were removed by two chloroform steps. Equal volumes of chloroform: isoamyl alcohol: phenol (24:24:1) (Sigma-Aldrich, Dublin, Ireland) was added, mixed thoroughly and centrifuged at $1500 \mathrm{~g}$ for $5 \mathrm{~min}$ (repeated twice). The upper layer was carefully removed and transferred to a new sterile tube. This step was repeated using equal volumes of chloroform: isoamyl alcohol (24:1), centrifuged for $5 \mathrm{~min}$ at $6000 \mathrm{~g}$. DNA was precipitated from the sample using 0.3 M Sodium Acetate solution pH 5.2 and 100\% ethanol ( $2 / 3$ volume of extract) following incubation at room temperature for $20 \mathrm{~min}$. Samples were centrifuged for $20 \mathrm{~min}$ at $14000 \mathrm{~g}$. The DNA was washed twice with $70 \%$ ethanol. DNA pellets were dried in a Rotovap (DNA speed Vac, DNA 110, Savant, Instruments. Inc. Holbrook, NY) on low power for 2-3 min to remove existing ethanol. DNA was resuspended in TE buffer $\mathrm{pH} 7.4$ and dissolved at $55^{\circ} \mathrm{C}$ for $1-2 \mathrm{~h}$. The quality and quantity of DNA was assessed by use of Nanodrop spectrophotometer (Nanodrop ND 1000) and running DNA on an agarose gel by electrophoresis followed by visualisation.

\subsection{Genome sequencing and annotation}

Phage DNA was sequenced with the Illumina MiSeq system at VIB Nucleomics Core, Belgium for phages vB_CsaM_leB and vB_CsaM_leN and at the University of Liverpool, Centre for Genomic Research, UK for phage vB_CsaM_leE (herein referred to as leB, leN, and leE, respectively). Libraries for phage leB and leN were created with a custom NEBNext ${ }^{\circledast}$ Ultra $^{\mathrm{TM}}$ DNA Kit and for phage leE the TruSeq DNA Nano LT library Sample Preparation Kit was used. The quality of each library preparation was assessed using the Agilent Bioanalyzer and Qubit measurements before being sequenced with paired end reads of $2 \times 250$ bp for phage leE and $2 \times 150$ bp for phage leB and leN. Reads were assembled for phage leB and leN with the CLC Bio Genomics Workbench v7.0 (Aarhus, Denmark) and for phage leE with the Spades genome assembler v.3.10 (St. Petersburg, Russia). Contigs were resolved with average coverage of $964 \times, 2,182 \times$ and $2030 \times$ for phages leB, leN and leE, respectively. Open reading frames (ORFs) encoding potential proteins were predicted with Glimmer (http://www. ncbi.nlm.nih.gov/genomes/MICROBES/glimmer_3.cgi) (Delcher et al., 1999) and GenemarkS (http://exon.gatech.edu/genemark/genemarks. cgi) (Besemer et al., 2001). Possible functions of these proteins were predicted with BLASTP (http://blast.ncbi.nlm.nih.gov/Blast.
cgi?PAGE $=$ Proteins) with tRNA genes being predicted with ARAGORN (http://130.235.46.10/ARAGORN/) (Laslett and Canback, 2004). Linear genome map comparison of the phages was created using Easyfig (Sullivan et al., 2011) with comparison of genome sequences utilising TBLASTX. Coregenes (Turner et al., 2013) was used for total proteome comparisons between phages leB, leE, and leN to Enterobacteria phage T4 (BLASTP threshold was set at 75\%) with PHACTs being used to predict the lifestyles of phages (http://www.phantome.org/PHACTS/ index.php) (McNair et al., 2012).

\subsection{Accession numbers}

The genomes of all three phages were submitted to Genbank under accession numbers KX443552, KX431559 B and KX431560 for phage leE, leB and leN, respectively.

\subsection{Electron microscopy}

Transmission electron microscopy (TEM) was performed as described previously (Kelly et al., 2012b, Sambrook and Russell, 2006). Briefly, a purified phage stock was prepared using $\mathrm{CsCl}_{2}$ gradient to achieve a titre in excess of $10^{8} \mathrm{pfu} / \mathrm{mL}$. The sample was negatively stained with $2 \%(\mathrm{w} / \mathrm{v})$ uranyl acetate on freshly prepared carbon films. Grids were analysed using a Tecnai 10 transmission electron microscope (FEI Company, Eindhoven, the Netherlands) at an acceleration voltage of $80 \mathrm{kV}$. Micrographs were taken with a MegaView G2 CCDcamera (EMSIS, Münster, Germany).

\subsection{Host range profiles of phages leB, leE, and leN}

The host range of each phage was examined against 21 different Cronobacter/Enterobacter strains, many of clinical origin, which were sourced from the Dairy Products Research Centre, DPC, Moorepark, Fermoy, Co. Cork, Ireland. Host range was determined by standard plaque assay technique as described previously (O'Flaherty et al., 2005).

\subsection{Effect of thermal treatment on phage infectivity}

For each phage, $3 \times 250 \mu \mathrm{L}$ phage suspensions $\left(\sim 1.0 \times 10^{8} \mathrm{pfu}\right.$ / $\mathrm{mL}$ ) were each placed either in the fridge at $4{ }^{\circ} \mathrm{C}$ or in water baths set to $37^{\circ} \mathrm{C}, 45^{\circ} \mathrm{C}, 55^{\circ} \mathrm{C}, 60^{\circ} \mathrm{C}, 72^{\circ} \mathrm{C}$ and $90^{\circ} \mathrm{C}$ respectively. Following $1 \mathrm{~h}$ incubation, $10 \mu \mathrm{L}$ volumes of serially diluted samples were spotted on C. sakazakii ATCC BAA 894 seeded agar. Plates were left to dry and placed in the incubator at $37{ }^{\circ} \mathrm{C}$ overnight. A thermocouple (Kane-May KM330, Inlec, UK) was placed in a control tube containing $250 \mu \mathrm{L}$ of phage buffer to ensure the desired temperature of the phage suspension was achieved for each experiment.

\subsection{Effect of $p H$ on phage infectivity}

For each phage, $3 \times 250 \mu \mathrm{L}$ aliquots of each phage suspension $\left(\sim 1.0 \times 10^{8} \mathrm{pfu} / \mathrm{mL}\right)$ were exposed to different $\mathrm{pH}$ values ranging from $\mathrm{pH} 2.0$ to $\mathrm{pH}$ 10.0. Phages were suspended in MP buffer [50 mM Tris pH 8, $150 \mathrm{mM} \mathrm{NaCl}, 10 \mathrm{mM} \mathrm{MgCl}_{2}, 2 \mathrm{mM} \mathrm{CaCl}_{2}$ ], which had been adjusted to desired $\mathrm{pH}$ values of $2.0,4.0,6.0,7.0,8.0$, and 10.0, respectively. The samples was incubated at $37^{\circ} \mathrm{C}$ for $1 \mathrm{~h}$, serially diluted and spotted $(10 \mu \mathrm{L})$ onto $C$. sakazakii ATCC BAA 894 seeded agar. Plates were left to dry and the plates were incubated at $37^{\circ} \mathrm{C}$ overnight.

\subsection{Preparation of phage cocktail}

The phage cocktail was prepared by combining equal volumes of each individual purified phage solution at $\sim 10^{9} \mathrm{pfu} / \mathrm{mL}$. The high titre phage preparation was stored at $4{ }^{\circ} \mathrm{C}$ until needed. 
2.12. Investigation of the antibacterial potential of the three phage cocktail against C. Sakazakii ATCC BAA 894 in four different brands of reconstituted infant milk formula

The three phage cocktail $\left(\sim 3 \times 10^{8} \mathrm{pfu} / \mathrm{mL}\right)$ was inoculated into each of the four reconstituted infant milk formulae containing $\sim 1 \times 10^{4} \mathrm{cfu} / \mathrm{mL}$ of $C$. sakazakii ATCC BAA 894 to a final volume of $10 \mathrm{~mL}$, and incubated with shaking at $37^{\circ} \mathrm{C}$ for $20 \mathrm{~h}$. Standard plate counts were performed on HiChrome ${ }^{\mathrm{TM}}$ Cronobacter spp. agar every $2 \mathrm{~h}$ over the $20 \mathrm{~h}$ period to quantify surviving cells. This was achieved by setting up a staggered experiment $12 \mathrm{~h}$ apart to account for the hours that could not be monitored during the night. PIF was prepared aseptically using sterile water $(10 \% \mathrm{w} / \mathrm{v})$ and mixed to ensure homogeneity. Positive controls were represented as samples containing the inoculated culture at $\sim 1 \times 10^{4} \mathrm{cfu} / \mathrm{mL}+\mathrm{MP}$ buffer only. Negative controls were represented as samples containing reconstituted infant formula only. All experiments were performed in triplicate and bacterial concentrations were expressed as mean $\mathrm{cfu} / \mathrm{mL}$ counts and standard deviation. In addition, parallel experiments were performed using a LUX labelled C. sakazakii ATCC BAA 894 strain supplemented with $500 \mu \mathrm{g} / \mathrm{mL}$ erythromycin in a microtitre plate assay and luminescence was monitored using the in vivo IVIS Imaging System (Xenogen Inc).

\subsection{Biofilm formation}

Static microtitre plate assays based on previous studies (Cerca et al., 2007) were used to investigate biofilm formation but with modifications. Briefly, an overnight pure culture of the following strains ( $C$. sakazakii ATCC BAA 894, C. sakazakii ATCC 29004, C. sakazakii DPC 6528, C. sakazakii DPC 8155 and C. muytjensi ATCC 51329) were each suspended in LB broth to an optical density equivalent of $0.5 \mathrm{McF}$ arland units. A selection of different broths (TSB, BHI and LB) supplemented with $1 \%$ and $2.5 \% \mathrm{D}-(+)$-glucose and four different brands of infant formula were tested for their ability to aid in biofilm formation. Cells were subsequently diluted into the appropriate solution to give a starting inoculum of $\sim 1 \times 10^{4} \mathrm{cfu} / \mathrm{mL}$. $200 \mu \mathrm{L}$ of the test sample (BHIglucose (g), LBg, TSBg or PIF) containing the culture was added to a sterile 96 well plate. $200 \mu \mathrm{L}$ of test media alone was added as a negative control. All wells were seeded in triplicate. Microtitre plates were incubated at $37^{\circ} \mathrm{C}$ for $48 \mathrm{~h}$ to allow biofilm formation. Following incubation, media was removed and wells were washed three times with $200 \mu \mathrm{L}$ of saline (Ringer's) solution using a multichannel pipette (Gilson) to remove media and planktonic cells. Microtitre plates were placed in a $50{ }^{\circ} \mathrm{C}$ incubator in an inverted position and allowed to dry for $1 \mathrm{~h}$. Formed biofilms were stained with $200 \mu \mathrm{L}$ of $1 \%$ crystal violet solution (Sigma Aldrich, UK) for $10 \mathrm{~min}$ at room temperature. The wells were washed to remove excess dye and left to dry before visually comparing the intensity of staining in the wells.

\subsection{Biofilm prevention with phage cocktail}

Following the identification of two C. sakazakii strains (C. sakazakii ATCC BAA 894, and C. sakazakii DPC 6528) that were capable of forming strong biofilms when grown in different types of infant formula (outlined above, 2.13.), the ability of the phage cocktail to prevent biofilm formation by these strains was investigated using a plate staining and live cell count assay.

\subsubsection{Plate staining assay}

The plate staining assay was performed as per the biofilm formation method described above with the following adjustments. At the start of the assay, $50 \mu \mathrm{L}$ of the phage cocktail $\left(\sim 3 \times 10^{8} \mathrm{pfu} / \mathrm{mL}\right)$ was added to $200 \mu \mathrm{L}$ of $C$. sakazakii culture in one set of wells in the microtitre plate, while $50 \mu \mathrm{L}$ of MP buffer was added to a second set of wells also containing $200 \mu \mathrm{L}$ of $C$. sakazakii culture. PIF alone was used as a negative control. The plates were incubated at $37^{\circ} \mathrm{C}$ for $48 \mathrm{~h}$, after which the media was poured off and biofilms were stained as described above. The stain was removed and the wells were washed gently. The plates were left to dry, after which $30 \%$ glacial acetic acid was added to solubilise the stain. The biofilm prevention ability of the phage cocktail was assessed by examining the optical density of the wells spectrophotometrically at $\mathrm{OD}_{590 \mathrm{~nm}}$.

\subsubsection{Live cell count assay}

The live cell count assay was performed as per the plate staining method with the following modifications. At the end of the $48 \mathrm{~h}$ incubation period, the media was removed and biofilms were washed three times with ringers to remove media and planktonic cells. Biofilms were resuspended by mechanical scraping in $100 \mu \mathrm{L}$ of saline solution (Ringer's) and immediately diluted and plated on to HiChrome ${ }^{\mathrm{TM}}$ Cronobacter spp. agar plates to determine $\mathrm{cfu} / \mathrm{mL}$ counts.

\section{Results}

\subsection{Phage isolation and morphology}

Following routine enrichments with the host bacterial strain $C$. sakazakii ATCC BAA 894, phage leB, leE and leN were isolated from slurry samples obtained from a cattle farmer in Clonakilty, Co. Cork, Ireland. All three phages formed clear plaques on the host strain following overnight incubation at $37^{\circ} \mathrm{C}$. Plaque size ranged from $2.0 \mathrm{~mm}$ to $4.5 \mathrm{~mm}$ in diameter on $0.4 \%$ semi-solid agar. Each phage was purified by successive single plaque isolation and propagation on the host strain. High titre phage suspensions of $\sim 10^{9} \mathrm{pfu} / \mathrm{mL}$, were recovered from LB agar plates using $5 \mathrm{ml}$ of MP buffer and stored at $4{ }^{\circ} \mathrm{C}$ until needed. Morphological characterisation of phages using TEM indicated that each belonged to the family Myoviridae (Fig. 1). The micrographs revealed phage $\mathrm{leB}, \mathrm{leE}$, and leN, to have moderately

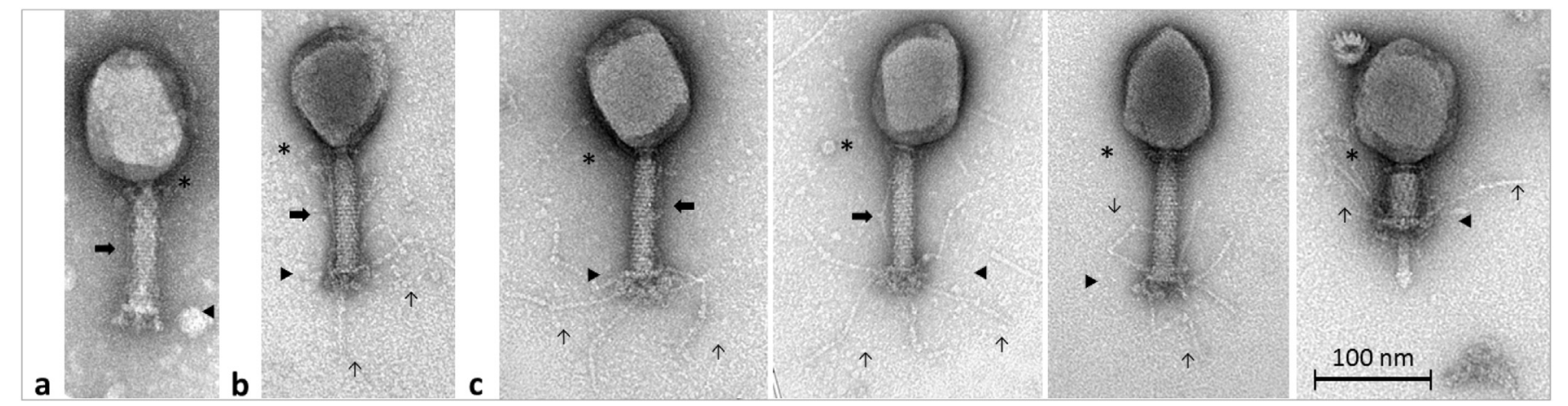

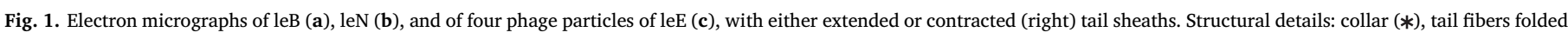

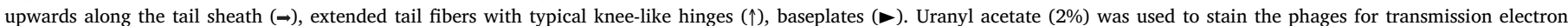
microscopy. 
Table 1

Phage dimensions.

\begin{tabular}{|c|c|c|c|}
\hline Phage & Head (nm) & Tail length (nm) incl. collar and baseplate & Free tail fibers $(\mathrm{nm})$ \\
\hline leB & $119.4 \pm 3.6 \times 89.7 \pm 3.6(n=6)$ & $116.0 \pm 1.5(n=5)$ & Not visible on micrographs \\
\hline leE & $115.1 \pm 3.5 \times 90.3 \pm 6.9(n=15)$ & $113.8 \pm 2.0(n=11)$ & $111.5 \pm 7.4(n=15)$ \\
\hline leN & $113.0 \pm 4.1 \times 91.9 \pm 2.5(n=16)$ & $114.6 \pm 2.4(n=18)$ & $114.0 \pm 7.9(n=15)$ \\
\hline
\end{tabular}

elongated heads accompanied by contractile tails, indicating that each belongs to the family Myoviridae, subtype A2 (Ackermann, 2001). Phage dimensions are represented in Table 1.

\subsection{Results from genome sequencing and annotation}

Through sequencing, genomes with sizes of $177,907 \mathrm{bp}, 181,570 \mathrm{bp}$ and 179,516 bp were obtained for phages leB, leE and leN, respectively, with a $\mathrm{G}+\mathrm{C} \%$ content of $45 \%$. Following bioinformatic annotation a total number of 281 ORFs, 284 ORFs and 286 ORFs were predicted for phages leB, leE and leN, respectively, with it being possible to annotate about 40\% (107 ORFs, 111 ORFs and 109 ORFs for leB, leE and leN, respectively) of their ORFs with a possible function (Supplementary Table 1). Additionally, one tRNA gene for glycine was predicted to be present in the genomes of all three phages (see supplemental data).

The genomes of these phage were found to be highly similar to each other (99\% identity with $94-99 \%$ coverage) with their closest known relatives at the nucleotide level being found to be T4 like phages Cronobacter phage GAP161 [JN882287.1] and Citrobacter phage Margaery [KT381880.1] (98-99\% identity with 92-97\% coverage).

At the proteomic level phages leB, leE and leN were found to have strong homology with Enterobacteria phage T4 [NC_00866] (Fig. 2), with phage leB sharing 116 homologs and phages leE and leN sharing 117 homologs with that of T4..It has been suggested that phages which share more $>40 \%$ of their proteins fall within phage genus boundaries (Lavigne et al., 2009). As these phages were found to share $>40 \%$ of their gene products they could be placed within the genus $\mathrm{T} 4$ virus.

PHACTs software confidently predicted that all these phages had lytic lifestyles, with average probability values exceeded 0.5 for phages leB (0.658), leE(0.663) and leN(0.659). Consistent with this prediction was that genes for integrases, excisionases or phage repressors were not identified in their genomes. Furthermore, no genes for toxins were detected.

\subsection{Phage host range}

Host range results revealed that our phages infected 12 (leB), 12 (leE) and $13(\mathrm{leN})$ of the 21 strains tested. All phages appeared to predominantly infect strains within the $C$. sakazakii species possessing the ability to plaque and lyse $10(\mathrm{leB}), 10(\mathrm{leE})$ and 11 (leN) of $15 \mathrm{C}$. sakazakii strains tested. In addition, as evidenced by the presence of plaques, all three phages were capable of infecting across genera and species, lysing C. muytjensi strain ATCC 51329 and E. cloacae strain NCTC 11933. However, when tested against other Enterobacter/ Cronobacter species (E. gergorviae NCTC 11431, E. cloacae NCTC 11590, C. malonaticus DPC 6531 and E. aerogenes NCTC 10006), lysis was not evident. The combination of all three phages resulted in $73 \%$ coverage across the Cronobacter strains tested (Table 2).

\subsection{Effect of temperature and $p H$ on phage infectivity}

All phages were tested for their ability to retain infectivity following exposure to a range of different temperature extremes. In general, it was observed that all phage retained infectivity between 4 and $50{ }^{\circ} \mathrm{C}$. While $\mathrm{a} \sim 2.5 \log$ reduction in titre was observed for phage leN following $1 \mathrm{~h}$ exposure to $50^{\circ} \mathrm{C}$, the titres of phage leB and leE were reduced by $\leq 6$ logs during this temperature challenge. No viable phages could be recovered from the lysates exposed for $1 \mathrm{~h}$ to $60{ }^{\circ} \mathrm{C}, 72{ }^{\circ} \mathrm{C}$ or $90^{\circ} \mathrm{C}$ (Fig. 3A).

The effect of $\mathrm{pH}$ on phage infectivity was investigated by exposing phage leB, leE and leN to a range of acidic, neutral and basic environments for $1 \mathrm{~h}$. In general, all three phages retained activity over pH 6 to pH 10. However, when exposed pH 10 for 1 h, a $5 \log , 3.5$ $\log$ and $6 \log$ reduction in phage titre was observed for phages leB, leE, and leN, respectively. No viable phages could be recovered from lysates following exposure to both $\mathrm{pH} 2$ and $\mathrm{pH} 4$ for $1 \mathrm{~h}$ (Fig. 3B).

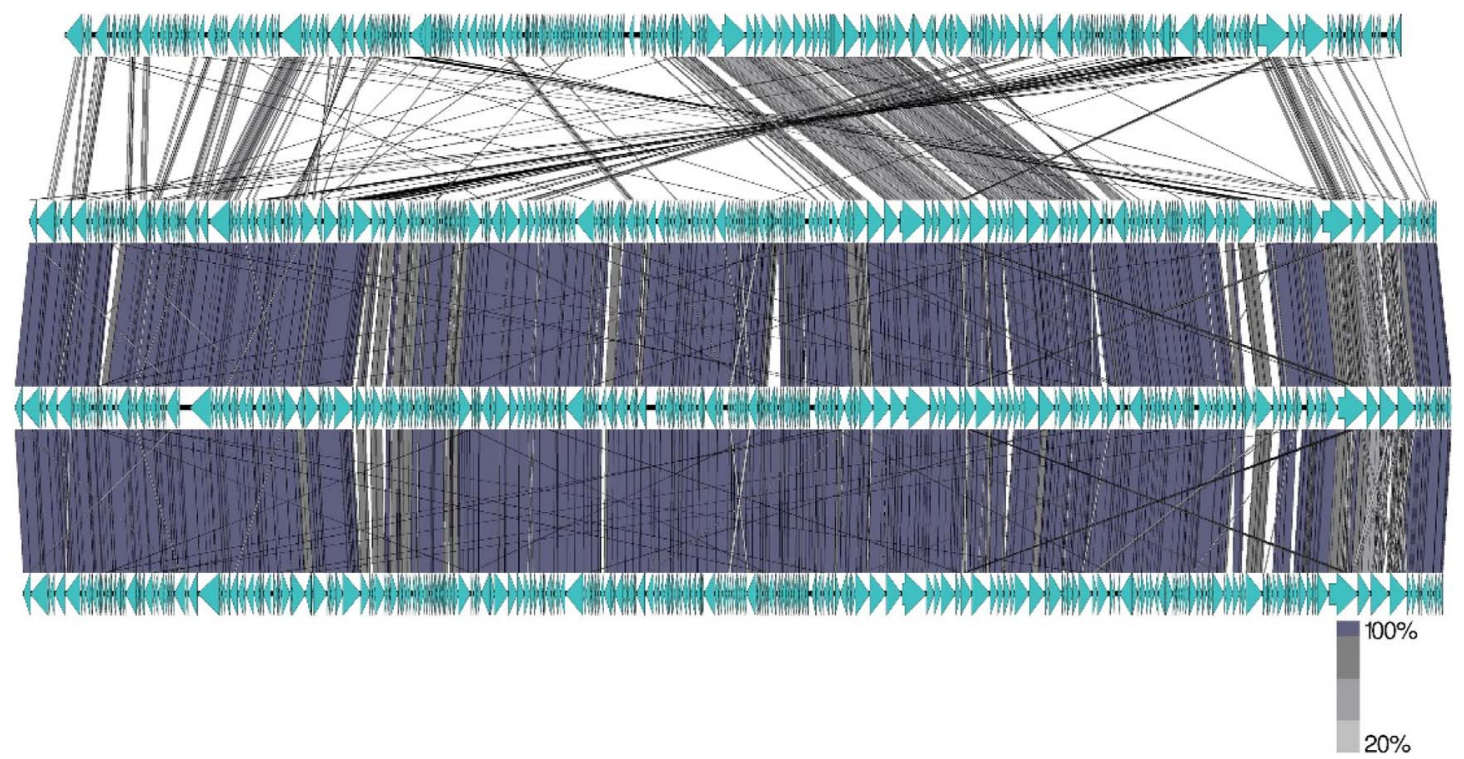

Enterobacteria phage T4

C. sakazakij phage vB_CsaM_leB (177,907 bp)

C. sakazakij phage vB_CsaM_leE (181,570 bp)

C. sakazakij phage vB_CsaM_leN (179,516 bp)

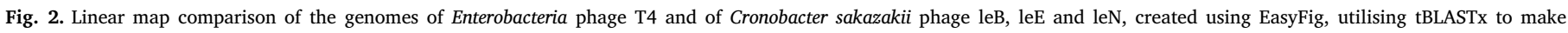

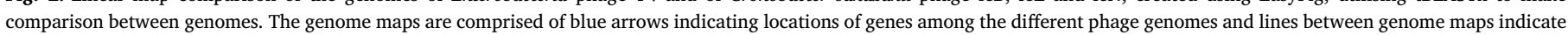
level of homology. (For interpretation of the references to colour in this figure legend, the reader is referred to the web version of this article.) 
Table 2

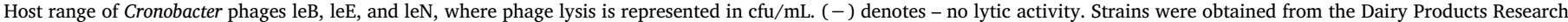
Centre, DPC, Moorepark, Fermoy, Co. Cork, Ireland.

\begin{tabular}{|c|c|c|c|c|}
\hline \multirow[t]{2}{*}{ Strain name } & \multirow[t]{2}{*}{ Origin } & \multicolumn{3}{|c|}{ Phage lysis (cfu/mL) } \\
\hline & & leB & leE & leN \\
\hline C. sakazakii ATCC BAA 894 & Powdered infant formula & $1.35 \mathrm{E}+08$ & $1.20 \mathrm{E}+08$ & $1.01 E+08$ \\
\hline C. sakazakii DPC 6529 & Tracheal aspirate & - & - & $5.10 \mathrm{E}+02$ \\
\hline C. sakazakii DPC 6522 & Blood & $8.00 \mathrm{E}+01$ & $1.19 \mathrm{E}+02$ & $2.10 \mathrm{E}+02$ \\
\hline C. sakazakii DPC 6523 & Cerebral spinal fluid & - & - & - \\
\hline C. sakazakii NCT 8155 & Tin of dried powdered milk & $1.20 \mathrm{E}+08$ & $1.17 \mathrm{E}+09$ & $1.05 E+09$ \\
\hline C. muytjensi ATCC 51329 & - & $2.20 \mathrm{E}+09$ & $1.20 \mathrm{E}+08$ & $1.90 \mathrm{E}+07$ \\
\hline C. sakazakii DPC 6524 & Stool & - & - & - \\
\hline C. sakazakii DSM 4485 & Child's throat & $7.50 \mathrm{E}+05$ & $5.00 \mathrm{E}+01$ & $1.70 \mathrm{E}+02$ \\
\hline C. malonaticus DPC 6531 & Brain tumour & - & - & - \\
\hline C. sakazakii ATCC 29004 & - & $1.89 \mathrm{E}+07$ & $2.70 \mathrm{E}+08$ & $4.50 \mathrm{E}+08$ \\
\hline C. sakazakii DPC 6530 & Bronchial alveolar lavage & $4.20 \mathrm{E}+02$ & $3.30 \mathrm{E}+04$ & $6.80 \mathrm{E}+04$ \\
\hline E. cloacae NCTC 11933 & Human/clinical isolate & $1.00 \mathrm{E}+01$ & $1.57 \mathrm{E}+08$ & $1.00 \mathrm{E}+02$ \\
\hline C. sakazakii DPC 6527 & Blood & $4.00 \mathrm{E}+01$ & $3.10 \mathrm{E}+02$ & $2.00 \mathrm{E}+01$ \\
\hline E. gergorviae NCTC 11431 & Human urinary tract & - & - & - \\
\hline E. cloacae NCTC 11590 & - & - & - & - \\
\hline E. aerogenes NCTC 10006 & Sputum & - & - & - \\
\hline C. sakazakii DPC 6526 & Blood & $1.10 \mathrm{E}+02$ & $1.98 \mathrm{E}+09$ & $4.00 \mathrm{E}+01$ \\
\hline C. sakazakii ATCC 12868 & - & - & - & - \\
\hline C. sakazakii DPC 6528 & Cerebral spinal fluid & $7.80 \mathrm{E}+07$ & $6.50 \mathrm{E}+08$ & $8.70 \mathrm{E}+07$ \\
\hline C. sakazakii DPC6525 & Urine & - & - & - \\
\hline C. sakazakii NCTC 11467 & Human throat & $1.76 \mathrm{E}+08$ & $3.10 \mathrm{E}+02$ & $2.00 \mathrm{E}+01$ \\
\hline
\end{tabular}

3.5. Investigation of the antibacterial potential of the three phage cocktail against C. sakazakii ATCC BAA 894 in four different brands of reconstituted infant milk formula

Cronobacter phages leB, leE, and leN were combined as part of a phage cocktail $\left(\sim 3 \times 10^{8} \mathrm{pfu} / \mathrm{mL}\right)$ to assess their ability to inhibit the growth of Cronobacter sakazakii ATCC BAA 894 in four different brands of infant formula. Bacterial counts of $\sim 1 \times 10^{4} \mathrm{cfu} / \mathrm{mL}$ were used for each biocontrol experiment, as this bacteria:phage concentration ratio was determined as the maximum inhibitory limit to successfully prevent outgrowth of $C$. sakazakii following the $20 \mathrm{~h}$ challenge. This contaminating concentration of cells is well in excess of the expected levels of $C$. sakazakii contamination typically found in reconstituted powdered infant formula ( $<1$ cell/100 $\mathrm{g}$ of PIF) (van Acker et al., 2001) and hence represents a clear indication of phage biocontrol potential. Following a $5 \mathrm{~h}$ incubation period, C. sakazakii concentrations were reduced to below the detection limit $(<10 \mathrm{cfu} / \mathrm{mL})$ in samples challenged with the phage cocktail. This level of inactivation was maintained over the $20 \mathrm{~h}$ challenge, where samples in the absence of the phage cocktail had reached bacterial concentrations in excess of $10^{9} \mathrm{cfu} / \mathrm{mL}$ (Fig. 4). Parallel experiments, where the LUX labelled $C$. sakazakii ATCC BAA 894 strain was employed to monitor cell viability, gave a similar result. Luminescence could not be detected from the wells challenged with the phage cocktail over the $20 \mathrm{~h}$ period, where significant relative light units (RLUs) were detected in the wells containing C. sakazakii LUX cells + MP buffer only (Fig. 5). At the end of the assay all wells were serially diluted and plated to determine the number of viable cells present in the sample. While the wells containing $C$. sakazakii LUX strain alone had reached a concentration of $\sim 10^{9} \mathrm{cfu} / \mathrm{mL}$, bacterial concentrations were reduced below the limit of detection $(<10 \mathrm{cfu} / \mathrm{mL})$ in the wells challenged with the phage cocktail.

\subsection{Biofilm formation}

Static microtitre plate assays were used to investigate biofilm formation by selected Cronobacter strains. Strain selection was dependant on individual phage infection profiles when tested against the 21 Cronobacter strains. Based on phage susceptibility testing (Table 2), five strains were selected for biofilm formation assessment. Biofilm formation experiments were performed in BHI, TSB and LB broths, supplemented with $1 \%$ and $2.5 \%$ glucose and also in four different brands of

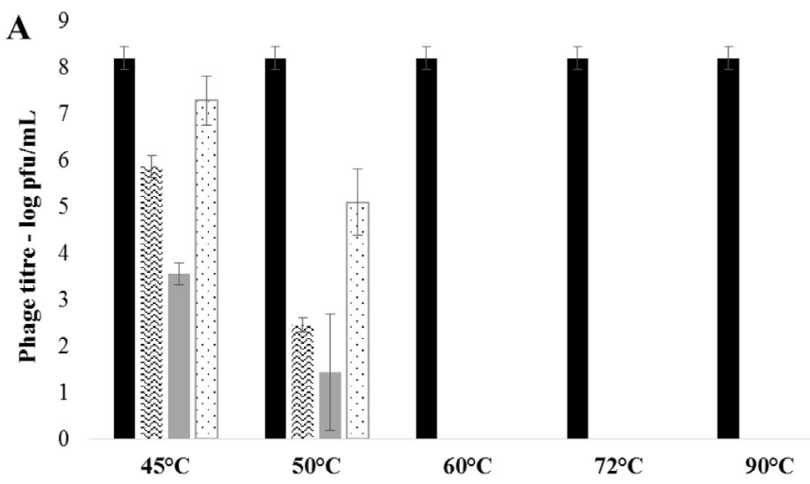

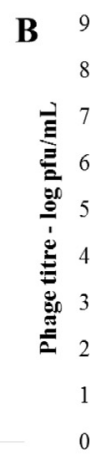

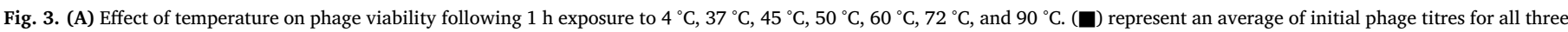

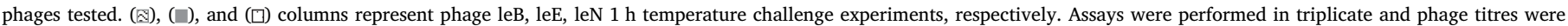

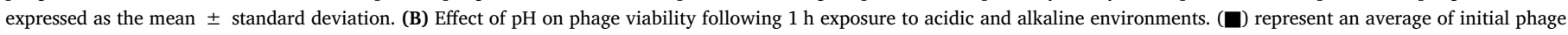

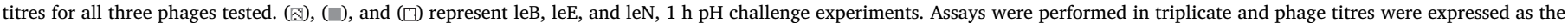
mean \pm standard deviation. 
PIF1

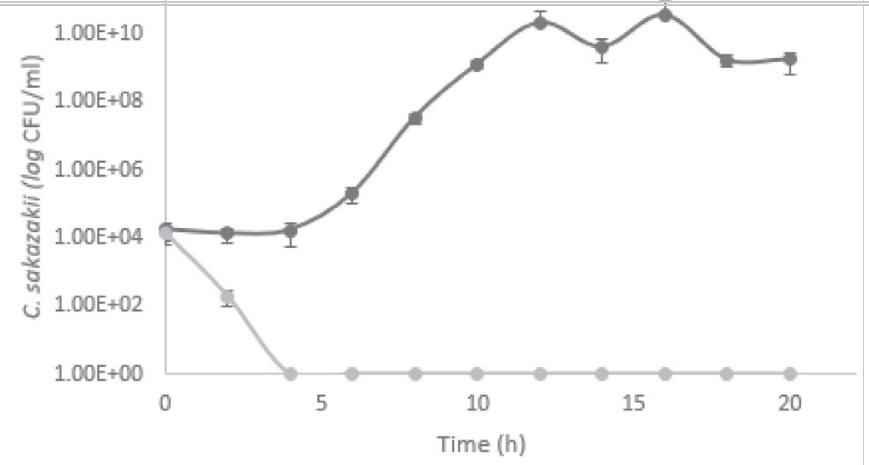

PIF3

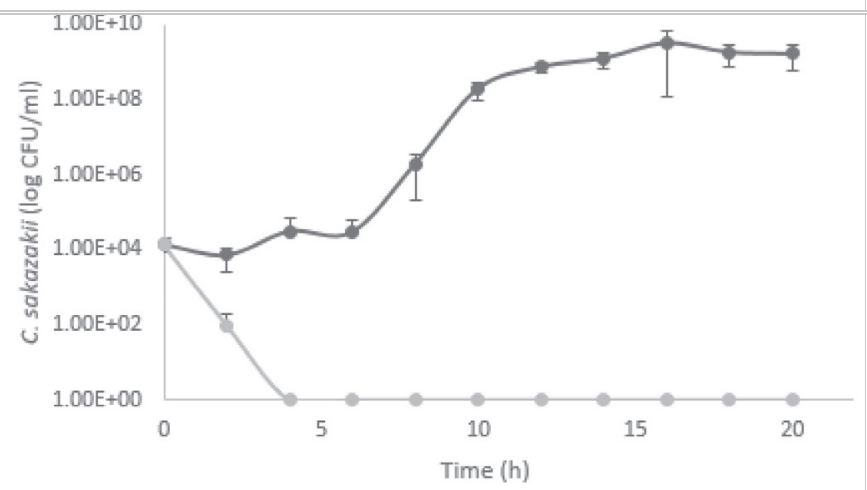

PIF2

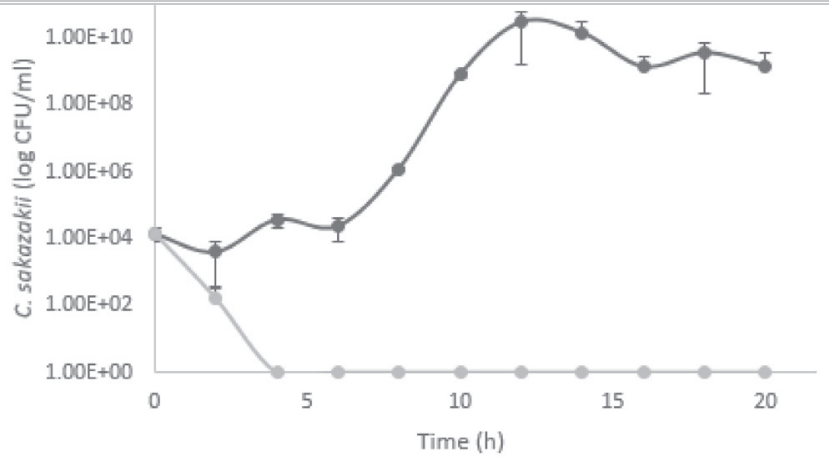

PIF4

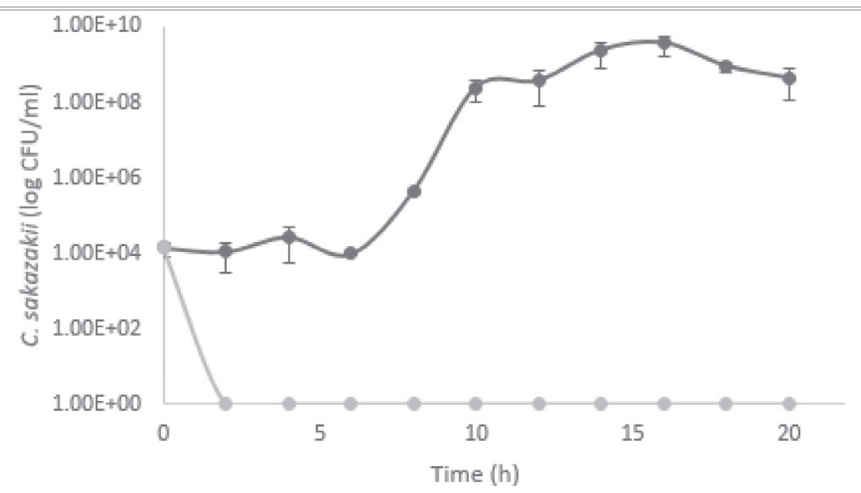

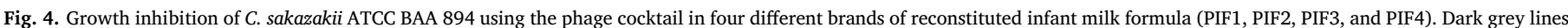

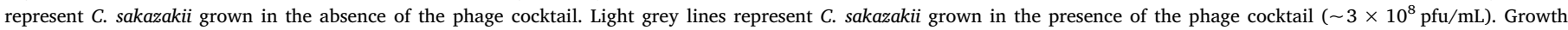
inhibition of $C$. sakazakii was determined by $\mathrm{cfu} / \mathrm{mL}$ counts. Assays were performed in triplicate and bacterial concentrations were expressed as the mean \pm standard deviation.

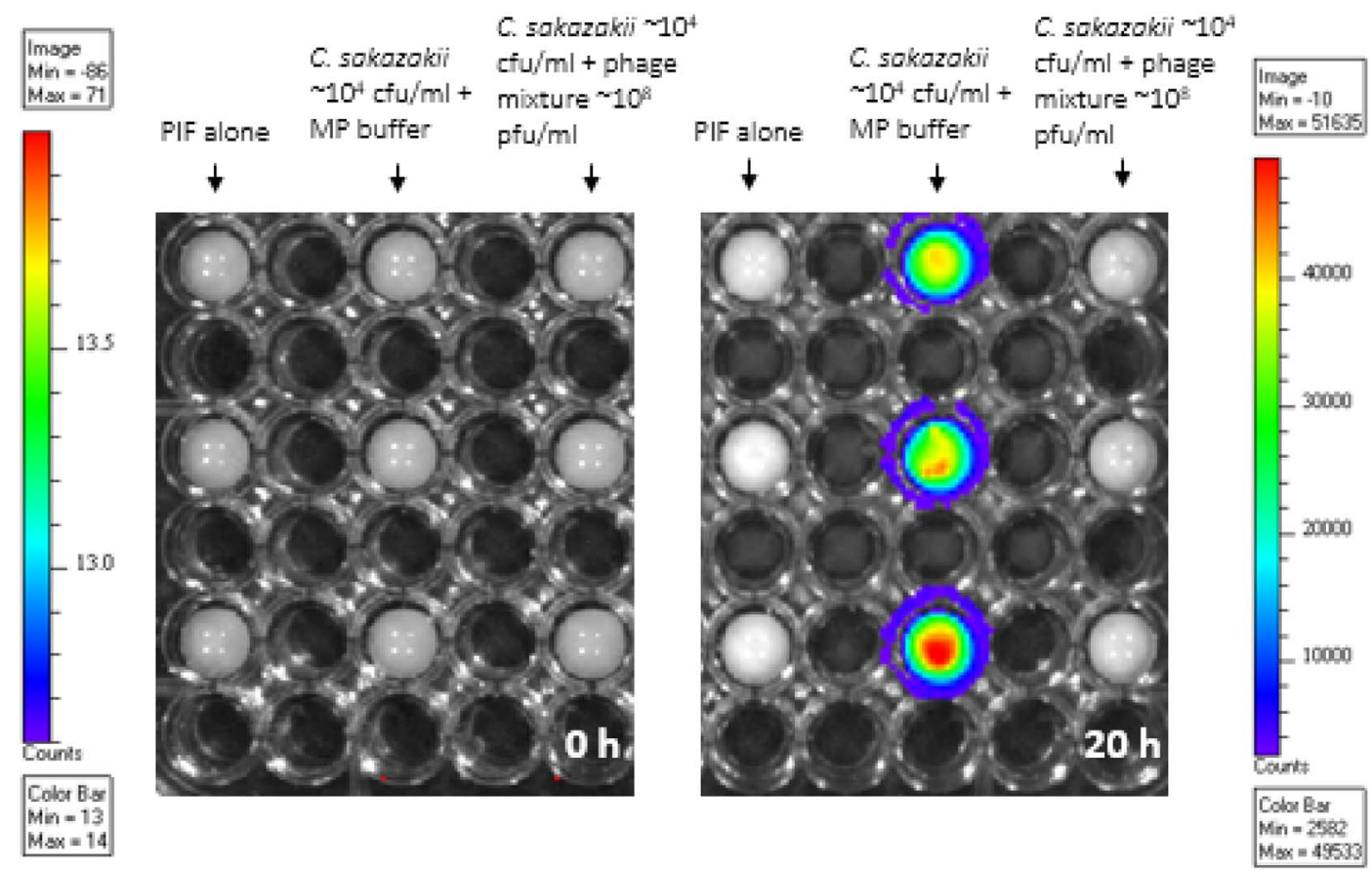

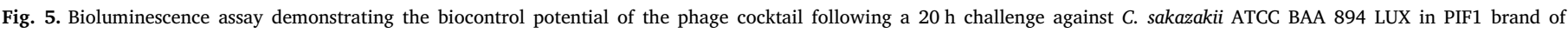

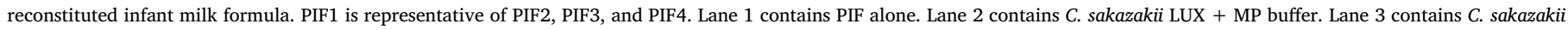
LUX + the phage cocktail at $\sim 3 \times 10^{8} \mathrm{pfu} / \mathrm{mL}$. 


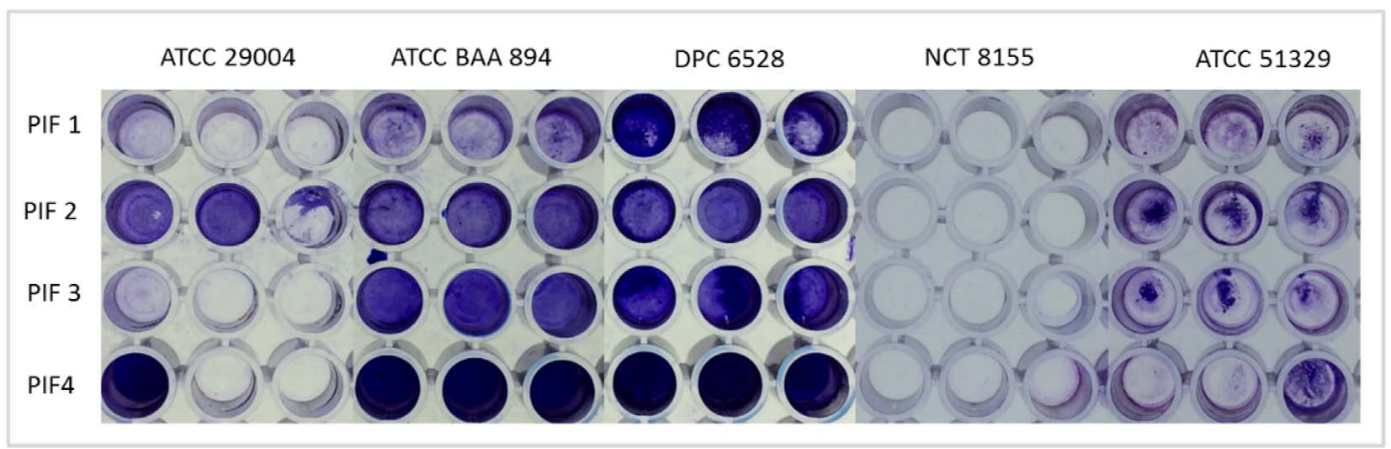

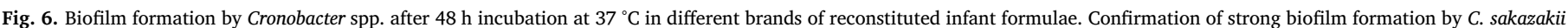

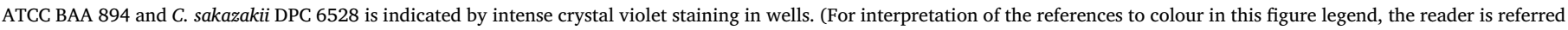
to the web version of this article.)

reconstituted infant milk formulae. Wells were inoculated with the selected Cronobacter strains and incubated at $37^{\circ} \mathrm{C}$ for $48 \mathrm{~h}$, followed by the addition of a $1 \%$ crystal violet stain to allow for direct visualisation of biofilms. It was found that the five Cronobacter strains were incapable of forming biofilms in BHI, TSB and LB alone and when supplemented with different concentrations of glucose (results not shown). However, C. sakazakii ATCC BAA 894 and C. sakazakii DPC 6528 were found to be strong biofilm producers when grown in each of the four different brands of PIF tested (Fig. 6).

\subsection{Biofilm prevention - plate staining and live cell count assay}

The first step of biofilm formation is initial attachment of bacteria to a solid surface. Accordingly, the effect of a high-titre, three-phage preparation $\left(\sim 3 \times 10^{8} \mathrm{pfu} / \mathrm{mL}\right)$ was assessed for its ability to prevent biofilm formation by C. sakazakii ATCC BAA 894 and C. sakazakii DPC
6528 in different brands of infant formula. Static microtitre plate assays were used and monitored by plate staining and live cell count assays.

Plates were stained following the $48 \mathrm{~h}$ biofilm prevention challenge. The stain was subsequently solubilised and measured at $\mathrm{OD}_{590 \mathrm{~nm}}$ to further assess the ability of the phage cocktail to prevent biofilm formation. This data is presented in Fig. 7. Results revealed the phage cocktail to be very effective at preventing biofilm formation, which was evident when compared to the control wells where strong biofilm formation was observed. In addition, parallel plate count experiments were performed in conjunction with the plate staining and solubilisation assays. Following the $48 \mathrm{~h}$ biofilm prevention challenge, bacterial concentrations were reduced to below the limit of detection ( $<10 \mathrm{cfu}$ / $\mathrm{mL}$ ) in the wells containing the phage cocktail, when compared to the control wells, where bacterial growth had reached levels of $\sim 10^{9} \mathrm{cfu} /$ $\mathrm{mL}$, again confirming the strong anti-biofilm potential of the phage cocktail against $C$. sakazakii in different brands of infant formula.

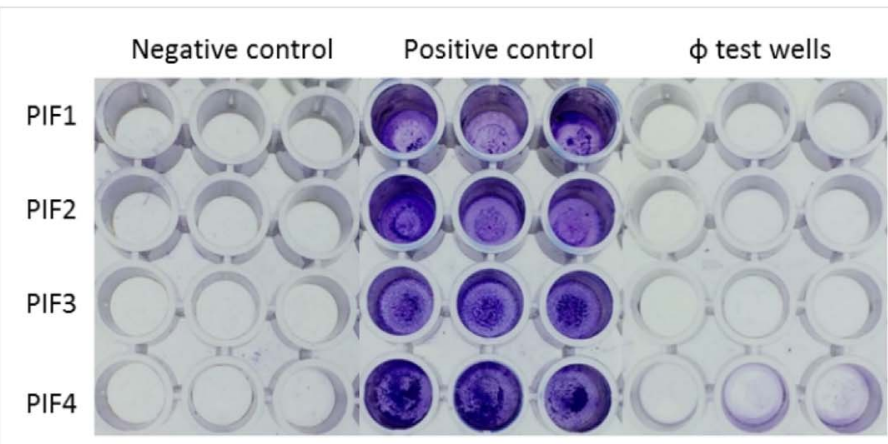

C. sakazakii ATCC BAA 894

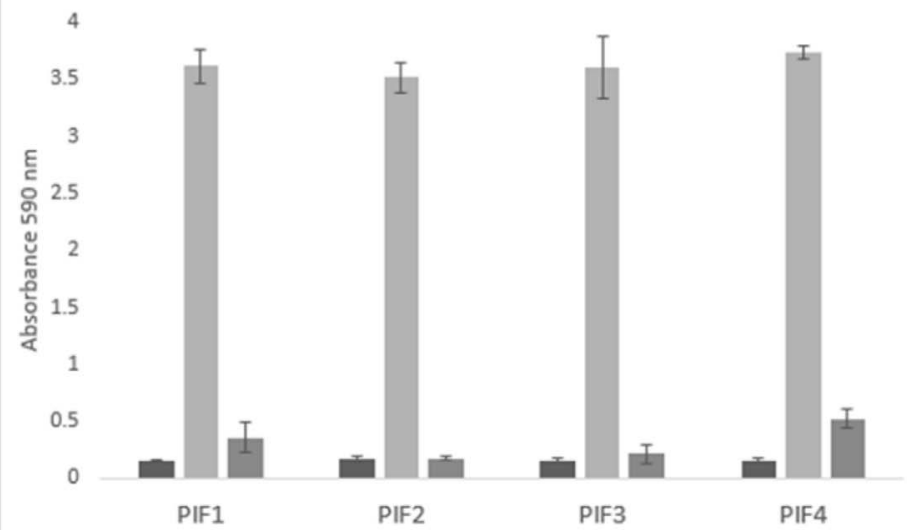

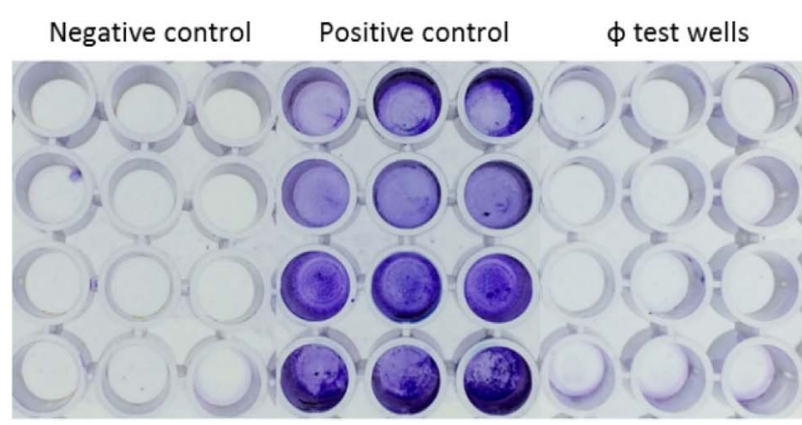

C. sakazakii DPC 6528

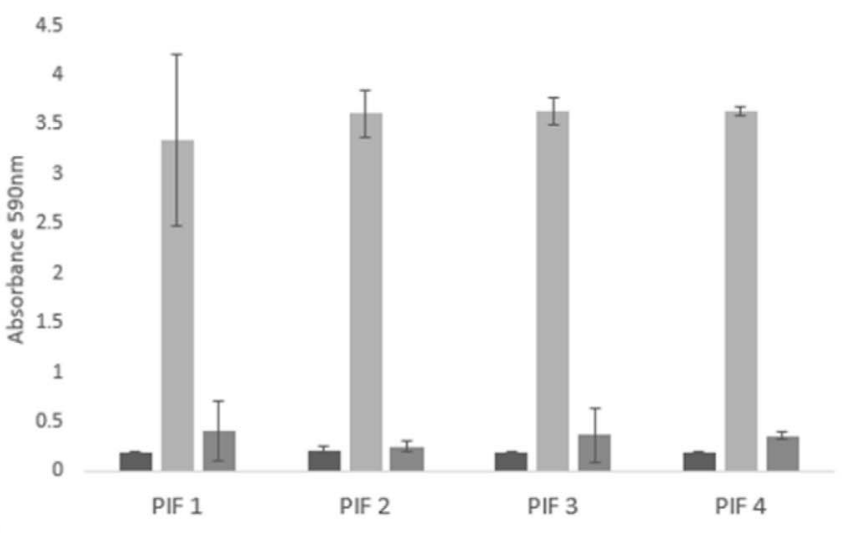

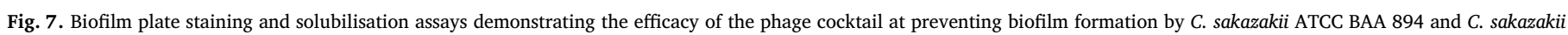
DPC 6528 following a $48 \mathrm{~h}$ challenge. () PIF only, () PIF containing C. sakazakii cells and MP buffer, and () PIF containing C. sakazakii cells and the three phage cocktail. 


\section{Discussion}

Consumption of contaminated reconstituted infant milk formula and concomitant $C$. sakazakii infections in infants and neonates has resulted in international efforts to improve existing pathogen control processes. Current intervention strategies have fallen short of providing powdered infant formula that is free from $C$. sakazakii contamination. Many novel technologies have been proposed in an effort to address this problem, some of which include, the use of hot water, gamma irradiation and high pressure processing to inactivate the pathogen prior to ingestion (Edelson-Mammel and Buchanan, 2004; Gonzalez et al., 2006; Lee et al., 2006). The natural biotherapeutic properties of phages are well recognised throughout the world, with many studies providing promising evidence of their biocontrol potential against several leading and emerging foodborne pathogens, while also demonstrating their suitability for use at each stage of the farm-to-fork continuum (Endersen et al., 2014; Goodridge and Bisha, 2011).

The rationale and motivation for performing the current study relates to the aforementioned reconstituted infant milk formula dilemma, and its associated health risks, in addition to the possibility of employing naturally occurring phages to alleviate this problem. We describe the isolation and characterisation of three novel Cronobacter phages and subsequent utilisation of a three phage preparation for biocontrol of C. sakazakii in different brands of infant formula. In addition to the activity and stability of the phages in infant formula, the anti-biofilm potential of the phage cocktail was also demonstrated. Three Cronobacter phages were isolated following routine enrichments of a variety of different environmental samples, including soil, slurry, activated sludge, river water, moss, grass, and wheat. While multiple phages were isolated from these sources, three phages which demonstrated particular promise for use as biocontrol agents against $C$. sakazakii were selected for further characterisation. Sewage has been recognised as a primary niche for many Enterobacteriaceae, so it is not uncommon that these and other Cronobacter phages were isolated from effluent environments (Kim et al., 2007; Zuber et al., 2008).

It is well documented that temperate phages from Enterobacteriaceae are known to harbour important bacterial virulence genes that can be readily transferred between bacteria. Determining phages to be absent of lysogenic capabilities is a primary consideration that must be taken into account if they are to be used in food related applications (Brüssow et al., 2004; Faruque and Mekalanos, 2012). As these phages have been determined to have lytic lifestyles and do not possess genes for toxic proteins they meet the required properties of phage intended for phage therapy applications. In addition, these phages have been determined to belong to the phage genus of.T4 virus,.phages from this genus have been deemed safe for phage therapy applications (Bruttin and Brüssow, 2005; Denou et al., 2009).

Phage susceptibility was assessed using 21 strains from Cronobacter/ Enterobacter genera. The broad host range attributed to phages leB, leE, and leN correlates well with previous findings. Loessner et al. (1993), demonstrated the broad host range of Enterobacter cloncae isolated phages, which were capable of cross infecting Panteo agglomerans, C. sakazakii, E. coli and Serratia marcescens (Loessner et al., 1993). In addition Zuber and co-authors also observed the broad host range capabilities of five combined E. sakazakii phages with an infection profile extending across several genera (Zuber et al., 2008).

Determining the environmental stability of phages considered for biocontrol in food and the food processing environment is essential. Common environmental extremes often associated with the food and food industry include low $\mathrm{pH}$ and high temperature pressures. Establishing the stress limits of each phage, permits appropriate and optimal application, and more effective biocontrol results overall. Each of the three phages were challenged for their ability to initiate host infection following exposure to a range of $\mathrm{pH}$ and temperature extremes. In general, all three phages retained maximum infectivity between $\mathrm{pH} 6$ and $\mathrm{pH}$. These findings compare well with those previously demonstrated, where the researchers found that $E$. coli phage T7 demonstrated optimum $\mathrm{pH}$ stability between $\mathrm{pH} 6$ and $\mathrm{pH} 8$ (Kerby et al., 1949). Similarly, in another study, phage T4 demonstrated optimum pH stability from pH 6-7.4 (Kłak et al., 2010), whereas coliphage $\lambda$ demonstrated very high stability across a wide $\mathrm{pH}$ range, where no significant decrease in titre was observed from $\mathrm{pH}$ 3-11 (Jepson and March, 2004). Temperature plays a fundamental role in the survival of phages. Optimal attachment, penetration, multiplication and the length of the latent period (in the case of temperate phages) are often dictated by temperature (Nasser and Oman, 1999; Olson et al., 2004; Yates et al., 1985). Higher than optimal temperatures are thought to extend the latent period, while lower than optimal temperatures are often thought to result in a reduced multiplication rate (Tey et al., 2009). In this current study, phages leB, leE, and leN were found to retain infectivity from 4 to $50^{\circ} \mathrm{C}$, with optimum infectivity occurring between 4 and $37^{\circ} \mathrm{C}$. Yang et al. (2010) evaluated the temperature stability of Acinetobacter phage $\mathrm{AB} 1$ which showed a higher tolerance to extreme temperatures, compared to phage leB, leE, and leN. Phage AB1 was very heat stable at $50{ }^{\circ} \mathrm{C}$ and $60{ }^{\circ} \mathrm{C}$, as only a slight drop in phage titre was observed following a $1 \mathrm{~h}$ challenge. At $70^{\circ} \mathrm{C}$ a significant number of the phages were inactivated, with only $0.52 \%$ of viable phages remained in the sample following $1 \mathrm{~h}$ incubation. Similarly, at $90{ }^{\circ} \mathrm{C},>99 \%$ of the phages had lost their infective ability following $15 \mathrm{~min}$ exposure to this temperature (Yang et al., 2010). In another study, the thermo-tolerance of staphylococcal phages was evaluated in milk. Researchers found that these phages were most stable when maintained at $4{ }^{\circ} \mathrm{C}$ for $8 \mathrm{~h}$, while observing a 20-30\% increase in phage inactivation when challenged at $22^{\circ} \mathrm{C}$ and $37^{\circ} \mathrm{C}$, respectively. While both phages survived very short exposure to high temperature extremes $\left(72{ }^{\circ} \mathrm{C}\right.$ for $\left.15 \mathrm{~s}\right)$, phage titres were reduced below the limit of detection after 1 min (Garcia et al., 2009).

In recent years, the application of phages for biocontrol of harmful pathogens in both pre- and postharvest food environments has become a noteworthy treatment alternative due to the increasing worldwide problem of antibiotic resistance and the reduction in the development of novel technologies for pathogen control. In this study, phage mediated killing and growth inhibition was demonstrated using a three-phage cocktail against $C$. sakazakii in four different brands of infant formula. Overall, it was found that the phage cocktail was effective at reducing contaminating $C$. sakazakii cells below the limit of detection $(<10 \mathrm{cfu} / \mathrm{mL})$ when bacterial concentration were used at a starting concentration of $\leq 1 \times 10^{4} \mathrm{cfu} / \mathrm{mL}$. This bacteria to phage concentration ratio was the maximum inhibitory limit to successfully prevent outgrowth of C. sakazakii over the $20 \mathrm{~h}$ challenge. It is interesting to note that despite slight differences in formula constitution, the growth rate of $C$. sakazakii was not affected for all formulas tested, nor did it impede phage infection. Our biocontrol results were similar to those outline by Zuber et al. (2008), who found that a high dose of $10^{8} \mathrm{pfu} / \mathrm{mL}$ of phage could effectively sterilise broth contaminated with both high $\left(10^{6} \mathrm{cfu} / \mathrm{mL}\right)$ and low $\left(10^{2} \mathrm{cfu} / \mathrm{mL}\right)$ pathogen counts (Zuber et al., 2008). In addition, Kim et al., 2007 reported inhibition of $C$. sakazakii at a range of different incubating temperatures when high titre $10^{9} \mathrm{pfu} / \mathrm{mL}$ single phage suspensions were used (Kim et al., 2007). Both Zuber et al. (2008), and Kim et al. (2007) also reported that when challenging low numbers of the contaminating pathogen with a reduced dose of the phage preparation, a delay in phage replication was evident up until bacterial counts had reached $\sim 10^{4} \mathrm{cfu} / \mathrm{mL}$. Only after crossing this threshold did phage replication occur but overall did not result in complete sterilisation of the sample. This would suggest that high concentrations of phage-based preparations are needed for complete sterilisation of a low quantity of target cells (Kasman et al., 2002; Weld et al., 2004). It is reported that the level of $C$. sakazakii contamination in PIF is very low ( $<1$ bacterial cell/100 g) (Holý and Forsythe, 2014), therefore improper handling is thought to contribute to bacterial growth and subsequent development of infection among low birth weight infants and neonates. The 
contaminating levels of $C$. sakazakii used in this study were much higher than levels typically found in PIF which demonstrates the efficacy of this phage cocktail for biocontrol of C. sakazakii in reconstituted infant formula.

Many phage-based intervention strategies have been documented against biofilm formation (Doolittle et al., 1995; Kelly et al., 2012a). Biofilms are a significant source of repeat contamination in dairy manufacturing plants, threatening the quality and safety of the manufactured produce, in addition to causing extensive economic losses to the food manufacturing industry due to produce recalls and corrosion of equipment (Gram et al., 2007). In addition, the persistence of foodborne pathogens, like C. sakazakii, on feeding areas, on the surfaces of equipment used in formula preparation, and within enteral feeding tubes, are also thought to contribute to neonatal outbreaks (Kim et al., 2007). Due to the high fatality rate associated with C. sakazakii infection among infants and neonates (up to 80\%), the destructive nature of the organism towards survivors, the ability of $C$. sakazakii to form biofilms and because of the problems associated with biofilm treatment and removal, it is clear that biofilm prevention is the preferable biocontrol option. We evaluated the biocontrol potential of the phage cocktail for its ability to prevent biofilm formation. Results indicated that the phage cocktail was very effective in preventing the establishment of biofilm where biofilm formation could not be detected for both strains tested for up to 2 days post-treatment. These results were similar to those outlined by Kelly et al. (2012a, 2012b), who demonstrated the efficacy of a modified phage cocktail for the prevention of Staphylococcus aureus biofilm formation. These researchers observed complete inhibition of biofilm formation over a $48 \mathrm{~h}$ time period (Kelly et al., 2012a). In addition, other studies have described the use of phages in an attempt to reduce biofilm formation. Hydrogelcoated catheters were impregnated with phage preparations and resulted in an approximate $90 \%$ reduction in both Proteus mirabilis and Escherichia coli formed biofilms when compared with un-treated controls (Carson et al., 2010). The anti-biofilm formation potential demonstrated by the phage cocktail in this study is promising and may have potential in future applications as perhaps a stand-alone treatment or used in conjunction with alternative antibacterials for the control and/or eradication of $C$. sakazakii contamination in food and the food production environment.

\section{Conclusion}

International efforts to develop novel strategies to improve the microbiological safety of PIF are ongoing. Although many advances in pathogen control have been made in recent years, cost and efficiency as well as the safety of preparation and nutritional stability are a problem. C. sakazakii contamination of PIF still remains an issue for public health concern. Phages have long been recognised for their inherent ability to control pathogens in food and food related environments, where other treatments have failed to do so. More and more, these non-destructive particles are continually gaining acceptance around the world as a viable alternative to antibiotics, and other treatment methods following the rise of multi-drug resistant bacteria. Accordingly, this study has presented three phages active against the infant formula associated pathogen, C. sakazakii. The phages were characterised in terms of temperature and $\mathrm{pH}$ stability and were combined to demonstrate the efficacy of using a three phage cocktail for biocontrol of C. sakazakii in four different brands of infant formula. In addition, their ability to effectively inhibit biofilm formation was also established. Our results highlight the promising potential of these phages for biocontrol of $C$. sakazakii contamination in infant formula and also as preventative biotherapeutic agents against biofilm formation. It should be noted that the isolation of additional phages capable of inactivating more resistant strains of $C$. sakazakii is a worthwhile endeavour. While $73 \%$ coverage is impressive, it could certainly be improved upon. Additional studies are now required in order to further this concept into practical use.

\section{Acknowledgments}

This work was funded by Technological Sector Research Strand III ref. CRS/07/CR03. Angela Back from MRI Kiel is acknowledged for technical assistance in preparations for electron microscopy. Hugo Oliveira and Rob Lavigne contributed to the genome sequencing analysis, supported by the KULeuven GOA (GOA/15/006) Grant Phagebiosystems.

\section{Appendix A. Supplementary data}

Supplementary data to this article can be found online at http://dx. doi.org/10.1016/j.ijfoodmicro.2017.04.009.

\section{References}

Ackermann, H.W., 2001. Frequency of morphological phage descriptions in the year 2000. Arch. Virol. 146, 843-857.

Al-Nabulsi, A.A., Osaili, T.M., Al-Holy, M.A., Shaker, R.R., Ayyash, M.M., Olaimat, A.N., Holley, R.A., 2009. Influence of desiccation on the sensitivity of Cronobacter spp. to lactoferrin or nisin in broth and powdered infant formula. Int. J. Food Microbiol. 136, 221-226.

Besemer, J., Lomsadze, A., Borodovsky, M., 2001. GeneMarkS: a self-training method for prediction of gene starts in microbial genomes. Implications for finding sequence motifs in regulatory regions. Nucleic Acids Res. 29, 2607-2618.

Bruttin, A., Brüssow, H., 2005. Human volunteers receiving Escherichia coli phage T4 orally: a safety test of phage therapy. Antimicrob. Agents Chemother. 49, 2874-2878.

Bigot, B., Lee, W.-J., McIntyre, L., Wilson, T., Hudson, J., Billington, C., Heinemann, J., 2011. Control of Listeria monocytogenes growth in a ready-to-eat poultry product using a bacteriophage. Food Microbiol. 28, 1448-1452.

Brady, C., Cleenwerck, I., Venter, S., Coutinho, T., De Vos, P., 2013. Taxonomic evaluation of the genus Enterobacter based on multilocus sequence analysis (MLSA): Proposal to reclassify E. nimipressuralis and E. amnigenus into Lelliottia gen. nov. as Lelliottia nimipressuralis comb. nov. and Lelliottia amnigena comb. nov., respectively, $E$. gergoviae and E. pyrinus into Pluralibacter gen. nov. as Pluralibacter gergoviae comb. nov. and Pluralibacter pyrinus comb. nov., respectively, E. cowanii, E. radicincitans, E. oryzae and E. arachidis into Kosakonia gen. nov. as Kosakonia cowanii comb. nov., Kosakonia radicincitans comb. nov., Kosakonia oryzae comb. nov. and Kosakonia arachidis comb. nov., respectively, and E. turicensis, E. helveticus and E. pulveris into Cronobacter as Cronobacter zurichensis nom. nov., Cronobacter helveticus comb. nov. and Cronobacter pulveris comb. nov., respectively, and emended description of the genera Enterobacter and Cronobacter. Syst. Appl. Microbiol. 36, 309-319.

Breeuwer, P., Lardeau, A., Peterz, M., Joosten, H., 2003. Desiccation and heat tolerance of Enterobacter sakazakii. J. Appl. Microbiol. 95, 967-973.

Bren, L., 2006. Bacteria-eating virus approved as food additive. FDA Consum. 41, 20-22.

Brüssow, H., Canchaya, C., Hardt, W.D., 2004. Phages and the evolution of bacterial pathogens: from genomic rearrangements to lysogenic conversion. Microbiol. Mol Biol. Rev. 68, 560-602.

Carlson, K., 2005. Appendix: working with bacteriophages: common techniques and methodological approaches. In: Bacteriophages: Biology and Applications, pp. 437-494.

Carlton, R., Noordman, W., Biswas, B., De Meester, E., Loessner, M., 2005. Bacteriophage P100 for control of Listeria monocytogenes in foods: genome sequence, bioinformatic analyses, oral toxicity study, and application. Regul. Toxicol. Pharmacol. 43, 301-312.

Carson, L., Gorman, S.P., Gilmore, B.F., 2010. The use of lytic bacteriophages in the prevention and eradication of biofilms of Proteus mirabilis and Escherichia coli. FEMS Immunol. Med. Microbiol. 59, 447-455.

Cerca, N., Oliveira, R., Azeredo, J., 2007. Susceptibility of Staphylococcus epidermidis planktonic cells and biofilms to the lytic action of staphylococcus bacteriophage K. Lett. Appl. Microbiol. 45, 313-317.

Chenu, J., Cox, J., 2009. Cronobacter ('Enterobacter sakazakii'): current status and future prospects. Lett. Appl. Microbiol. 49, 153-159.

Donlan, R.M., Costerton, J.W., 2002. Biofilms: survival mechanisms of clinically relevant microorganisms. Clin. Microbiol. Rev. 15, 167-193.

Doolittle, M., Cooney, J., Caldwell, D., 1995. Lytic infection of Escherichia coli biofilms by bacteriophage T4. Can. J. Microbiol. 41, 12-18.

Delcher, A.L., Harmon, D., Kasif, S., White, O., Salzberg, S.L., 1999. Improved microbial gene identification with GLIMMER. Nucleic Acids Res. 27, 4636-4641.

Denou, E., Bruttin, A., Barretto, C., Ngom-Bru, C., Brüssow, H., Zuber, S., 2009. T4 phages against Escherichia coli diarrhea: potential and problems. Virology 388, 21-30.

Edelson-Mammel, S.G., Buchanan, R.L., 2004. Thermal inactivation of Enterobacter sakazakii in rehydrated infant formula. J. Food Prot. 67, 60-63.

Ellis, D., Whitman, P., Marshall, R., 1973. Effects of homologous bacteriophage on growth of Pseudomonas fragi WY in milk. Appl. Microbiol. 25, 24-25.

Endersen, L., Coffey, A., Neve, H., McAuliffe, O., Ross, R.P., O'Mahony, J.M., 2013. Isolation and characterisation of six novel mycobacteriophages and investigation of their antimicrobial potential in milk. Int. Dairy J. 28, 8-14.

Endersen, L., O'Mahony, J., Hill, C., Ross, R.P., McAuliffe, O., Coffey, A., 2014. Phage therapy in the food industry. Annu. Rev. Food Sci. Technol. 5, 327-349.

Faruque, S.M., Mekalanos, J.J., 2012. Phage-bacterial interactions in the evolution of 
toxigenic vibrio cholerae. Virulence 3, 556-565.

Food and Agriculture Organization/World Health Organization (FAO/WHO), 2008 Enterobacter sakazakii (Cronobacter spp.) in powdered follow-up formulae. MRA series. Available at. http://www.who.int/foodsafety/publications/micro/MRA followup. pdf Date last accessed 24/04/17.

Forsythe, S.J., 2005. Enterobacter sakazakii and other bacteria in powdered infant milk formula. Matern. Child Nutr. 1, 44-50.

Friedemann, M., 2007. Enterobacter sakazakii in food and beverages (other than infant formula and milk powder). Int. J. Food Microbiol. 116, 1-10.

Friedemann, M., 2009. Epidemiology of invasive neonatal Cronobacter (Enterobacter sakazakii) infections. Eur. J. Clin. Microbiol. Infect. Dis. 28, 1297-1304.

Fsanz, F., 2012. Approval report-application A1045 in. Bacteriophage preparation P100 as processing aid.

Garcia, P., Madera, C., Martinez, B., Rodriguez, A., Suarez, J.E., 2009. Prevalence of bacteriophages infecting Staphylococcus aureus in dairy samples and their potential as biocontrol agents. J. Dairy Sci. 92, 3019-3026.

Gonzalez, S., Flick, G., Arritt, F., Holliman, D., Meadows, B., 2006. Effect of high-pressure processing on strains of Enterobacter sakazakii. J. Food Prot. 69, 935-937.

Goodridge, L.D., Bisha, B., 2011. Phage-based biocontrol strategies to reduce foodborne pathogens in foods. Bacteriophage 1, 130-137.

Gram, L., Bagge-Ravn, D., Ng, Y.Y., Gymoese, P., Vogel, B.F., 2007. Influence of food soiling matrix on cleaning and disinfection efficiency on surface attached Listerid monocytogenes. Food Control 18, 1165-1171.

Healy, B., Cooney, S., O'Brien, S., Iversen, C., Whyte, P., Nally, J., Callanan, J.J., Fanning, S., 2010. Cronobacter (Enterobacter sakazakii): an opportunistic foodborne pathogen. Foodborne Pathog. Dis. 7, 339-350.

Himelright, I., 2002. Enterobacter sakazakii infections associated with the use of powdered infant formula-Tennessee, 2001. J. Am. Med. Assoc. 287, 2204-2205.

Hodgson, K., 2013. Bacteriophage therapy. Microbiol. Aust. 34, 28-31.

Holý, O., Forsythe, S., 2014. Cronobacter spp. as emerging causes of healthcare-associated infection. J. Hosp. Infect. 86, 169-177.

Hunter, C., Bean, J., 2013. Cronobacter: an emerging opportunistic pathogen associated with neonatal meningitis, sepsis and necrotizing enterocolitis. J. Perinatol. 33, 581-585.

ICMSF, 2002. Microorganisms in Foods 7. Microbiological testing in food safety management. Kluwer Academic / Plenum Publishers, New York, USA.

Iversen, C., Forsythe, S., 2004. Isolation of Enterobacter sakazakii and other Enterobacteriaceae from powdered infant formula milk and related products. Food Microbiol. 21, 771-777.

Iversen, C., Lane, M., Forsythe, S., 2004. The growth profile, thermotolerance and biofilm formation of Enterobacter sakazakii grown in infant formula milk. Lett. Appl. Microbiol. 38, 378-382.

Iversen, C., Lehner, A., Mullane, N., Bidlas, E., Cleenwerck, I., Marugg, J., Fanning, S., Stephan, R., Joosten, H., 2007. The taxonomy of Enterobacter sakazakii: proposal of a new genus Cronobacter gen. nov. and descriptions of Cronobacter sakazakii comb. nov. Cronobacter sakazakii subsp. sakazakii, comb. nov., Cronobacter sakazakii subsp. malonaticus subsp. nov., Cronobacter turicensis sp. nov., Cronobacter muytjensii sp. nov., Cronobacter dublinensis sp. nov. and Cronobacter genomospecies 1. BMC Evol. Biol. 7, 64 .

Jepson, C.D., March, J.B., 2004. Bacteriophage lambda is a highly stable DNA vaccine delivery vehicle. Vaccine 22, 2413-2419.

Joseph, S., Cetinkaya, E., Drahovska, H., Levican, A., Figueras, M.J., Forsythe, S.J., 2012. Cronobacter condimenti sp. nov., isolated from spiced meat, and Cronobacter universalis sp. nov., a species designation for Cronobacter sp. genomospecies 1, recovered from a leg infection, water and food ingredients. Int. J. Syst. Evol. Microbiol. 62, 1277-1283.

Kandhai, M.C., Reij, M.W., Gorris, L.G., Guillaume-Gentil, O., van Schothorst, M., 2004. Occurrence of Enterobacter sakazakii in food production environments and households. Lancet 363, 39-40.

Kasman, L.M., Kasman, A., Westwater, C., Dolan, J., Schmidt, M.G., Norris, J.S., 2002. Overcoming the phage replication threshold: a mathematical model with implications for phage therapy. J. Virol. 76, 5557-5564.

Kelly, D., McAuliffe, O., Ross, R., Coffey, A., 2012a. Prevention of Staphylococcus aureus biofilm formation and reduction in established biofilm density using a combination of phage K and modified derivatives. Lett. Appl. Microbiol. 54, 286-291.

Kelly, D., O'Sullivan, O., Mills, S., McAuliffe, O., Ross, R.P., Neve, H., Coffey, A., 2012 b.
Genome sequence of the phage clP1, which infects the beer spoilage bacterium Pediococcus damnosus. Gene 504, 53-63.

Kerby, G., Gowdy, R., Dillon, E., Dillon, M., Csâky, T., Sharp, D., Beard, J., 1949. Purification, $\mathrm{pH}$ stability and sedimentation properties of the T7 bacteriophage of Escherichia coli. J. Immunol. 63, 93-107.

Keren, I., Kaldalu, N., Spoering, A., Wang, Y., Lewis, K., 2004. Persister cells and tolerance to antimicrobials. FEMS Microbiol. Lett. 230, 13-18.

Kim, K.-P., Klumpp, J., Loessner, M.J., 2007. Enterobacter sakazakii bacteriophages can prevent bacterial growth in reconstituted infant formula. Int. J. Food Microbiol. 115, 195-203.

Kłak, M., Międzybrodzki, R., Bubak, B., Jończyk, E., Weber-Dąbrowska, B., Górski, A. 2010. Studies on the gastrointestinal transit and blood penetration of a therapeutic staphylococcal bacteriophage. Abstract no. 209. In: First International Congrogress. Viruses of Microbes, Paris, .

Kropinski, A.M., Clokie, M.R., 2009. Bacteriophages: methods and protocols. In: Molecular and Applied Aspects. Volume 2 Humana Press.

Lai, K.K., 2001. Enterobacter sakazakii infections among neonates, infants, children, and adults: case reports and a review of the literature. Medicine 80, 113-122.

Laslett, D., Canback, B., 2004. ARAGORN, a program to detect tRNA genes and tmRNA genes in nucleotide sequences. Nucleic Acids Res. 32, 11-16.

Lee, J., Oh, S., Kim, J., Yook, H., Byun, M., 2006. Gamma radiation sensitivity of Enterobacter sakazakii in dehydrated powdered infant formula. J. Food Prot. 69, 1434-1437.

Loessner, M.J., Neugirg, E., Zink, R., Scherer, S., 1993. Isolation, classification and molecular characterization of bacteriophages for Enterobacter species. J. Gen. Microbiol. 139, 2627-2633.

Nasser, A.M., Oman, S.D., 1999. Quantitative assessment of the inactivation of pathogenic and indicator viruses in natural water sources. Water Res. 33, 1748-1752.

Nazarowec-White, M., Farber, J., 1997a. Enterobacter sakazakii: a review. Int. J. Food Microbiol. 34, 103-113.

Nazarowec-White, M., Farber, J., 1997b. Thermal resistance of Enterobacter sakazakii in reconstituted dried-infant formula. Lett. Appl. Microbiol. 24, 9-13.

McNair, K., Bailey, B.A., Edwards, R.A., 2012. PHACTS, a computational approach to classifying the lifestyle of phages. Bioinformatics 28, 614-618.

O'Flaherty, S., Ross, R., Flynn, J., Meaney, W., Fitzgerald, G., Coffey, A., 2005. Isolation and characterization of two anti-staphylococcal bacteriophages specific for pathogenic Staphylococcus aureus associated with bovine infections. Lett. Appl. Microbiol. 41, 482-486.

Olson, M.R., Axler, R.P., Hicks, R.E., 2004. Effects of freezing and storage temperature on MS2 viability. J. Virol. Methods 122, 147-152.

Lavigne, R., Darius, P., Summer, E.J., Seto, D., Mahadevan, P., Nilsson, A.S., Ackermann, H.W., Kropinski, A.M., 2009. Classification of Myoviridae bacteriophages using protein sequence similarity. BMC Microbiol. 9, 224.

Sambrook, J., Russell, D.W., 2006. Purification of bacteriophage $\lambda$ particles by isopycnic centrifugation through $\mathrm{CsCl}$ gradients. Cold Springs Harb. Protoc (Pdb-prot 3968).

Sullivan, M.J., Petty, N.K., Beatson, S.A., 2011. Easyfig: a genome comparison visualizer. Bioinformatics 27, 1009-1010.

Tey, B.T., Ooi, S.T., Yong, K.C., Ng, M.Y.T., Ling, T.C., Tan, W.S., 2009. Production of fusion $\mathrm{m} 13$ phage bearing the di-sulphide constrained peptide sequence (C-WSFFSNIC) that interacts with hepatitis B core antigen. Afr. J. Biotechnol. 8, 268-273.

Turner, D., Reynolds, D., Seto, D., Mahadevan, P., 2013. CoreGenes3.5: A webserver for the determination of core genes from sets of viral and small bacterial genomes. BMC Res. 6, 140.

van Acker, J., de Smet, F., Muyldermans, G., Bougatef, A., Naessens, A., Lauwers, S., 2001. Outbreak of necrotizing enterocolitis associated with Enterobacter sakazakii in powdered milk formula. J. Clin. Microbiol. 39, 293-297.

Weld, R.J., Butts, C., Heinemann, J.A., 2004. Models of phage growth and their applicability to phage therapy. J. Theor. Biol. 227, 1-11.

Yang, H., Liang, L., Lin, S., Jia, S., 2010. Isolation and characterization of a virulent bacteriophage AB1 of Acinetobacter baumannii. BMC Microbiol. 10, 131.

Yates, M.V., Gerba, C.P., Kelley, L.M., 1985. Virus persistence in groundwater. Appl Environ. Microbiol. 49, 778-781.

Zuber, S., Boissin-Delaporte, C., Michot, L., Iversen, C., Diep, B., Brüssow, H., Breeuwer, P., 2008. Decreasing Enterobacter sakazakii (Cronobacter spp.) food contamination level with bacteriophages: prospects and problems. Microb. Biotechnol. 1, 532-543. 